\title{
Developing Institutional Arrangements for Sustainable Development within Mineral Rich Resource Countries: the Case of Mongolia
}

\begin{abstract}
A primary goal of the article is to explore the theoretical understanding among scholars about how institutional arrangements for sustainable local development partnerships in mineral resource-rich countries are created. A success factor for implementing sustainable development goals (SDGs) is creating a proper institutional arrangement.

Interviews and questionnaires, a mixed research method, were completed with officials and citizens from selected provinces. We reached to the following results: among others there is a weak understanding of partnership-related local community development among stakeholders. Therefore, long term strategic planning and management which involves all parties in the decision-making process should be created. In addition, building both horizontal and vertical institutional arrangements that provide for the participation of related stakeholders is an essential element for building successful and sustainable local development partnerships.
\end{abstract}

Keywords: sustainable development, stakeholders' participation, institutional arrangements, strategic planning, mining sector management

Received: 30 August 2020; accepted: 13 October 2020

(C) 2021 Authors. This is an open access publication, which can be used, distributed and reproduced in any medium according to the Creative Commons CC-BY 4.0 License.

1 National University of Mongolia, Department of Public Administration, School of International Relations and Public Administration,

email: burmaan@num.edu.mn, ORCID ID: https://orcid.org/0000-0002-0783-7300

2 National University of Mongolia, Department of Public Administration, School of International Relations and Public Administration, email: baasanjav_ue@num.edu.mn (corresponding author)

ORCID ID: https://orcid.org/0000-0003-2445-0252 


\section{Introduction}

The 2030 Agenda for Sustainable Development, adopted at the United Nations (UN) Sustainable Development Summit in September 2015, has, at its core, a set of seventeen Sustainable Development Goals (SDGs) and 169 targets. The SDGs apply to all countries, both developing and developed, and embody a fundamental commitment to leaving no one behind. Therefore, any policy, decision or measure should be assessed with respect to its impact on these SDG goals and targets. The "no one left behind" principle also places high demands on institutional arrangements for the SDGs. Governments have to be aware that the needs of all, and especially of marginalized groups, will need an institutionalized mechanism to be heard. This could take the form of a dedicated ministerial unit, structural provision for parliamentary work, multi-stakeholder committee or a watchdog function by a non-governmental organization.

According to the multi-stakeholder approach used by the UN, multi-stakeholder partnerships between business, NGOs, Governments, the UN and other actors should play an important role in the implementation of the agenda [1]. Multi-stakeholder partnerships also function as cross-sector sustainable development partnerships which provide important opportunities for collaboration and cooperation [2]. Thus, establishing sustainable integrated partnerships beween local governments, citizens, civil society organizations and private enterprises that operate is similar regions can create value for the future. In addition, ensuring equal participation in sustainable development efforts will also facilitate the establishment of effective control mechanisms and cooperation. Especially, correct communication among stakeholders is the key success factor of good relationship between them [3]. Yet, there are many issues involved in achieving such collaboration and cooperation.

For the Mongolian case, aimags (i.e., provinces) that are rich in natural resources, must address numerous issues. Some of these issues include: governance, enhancing the quality as well as the inclusive nature of participation in development. In addition, social responsibility, ensuring that the functions and responsibilities of central state and local administrations properly address local development issues, as well as enhancing collaboration and cooperation among public administrations, mining companies and private enterprises, non-governmental organizations and citizens with the goal of positively, influencing future outcomes are other essential issues that must be addressed.

One of the most important institutional arrangements for the SDGs is horizontal coordination between different ministries, and between departments of a ministry, whose policies effect the same economic sector. In policy-making, the fragmentation and narrowed perspectives caused by the lack of horizontal coordination between and within government agencies leads to the neglect of critical aspects of policy oftentimes because such aspects are not considered an agency's responsibility. In addition, the challenges of achieving true horizontal coordination arise from disincentives 
to policy integration from the perspectives of sectorial actors. The necessity to coordinate policy content with other sectorial institutions, or even to collaborate, requires much short-term effort while any successes tend to manifest themselves in the long-term. Even then, achievements cannot usually be attributed to institutions individually. Thus, achieving effective horizontal coordination is difficult.

Yet, there are good reasons for seeking horizontal coordination, especially among the various sectorial organizations of government. The benefits of such coordination are many; including: the sharing of expertise of specialized departments, more effective and efficient decision-making, as well as clarity of responsibility that comes from an established hierarchy. However, it appears that the SDGs have shifted attention away from efforts of collaboration and cooperation to policy integration. Therefore, the development of new institutional arrangements, which do not overstrain existing sectorial organizations while at the same time allow for horizontal coordination, is required.

It is also not possible to arrange an effective horizontal coordination simply by invoking the top-down principle whereby, some chief executive issues a mandate. Similarly, the practice found in some countries of assigning one ministry the responsibility of policy coordination while the other ministries are responsible for sectorial policies may not be very promising either. Instead, an overarching sustainability strategy is required, one which integrates the sectorial perspective of each individual ministry. Horizontal coordination must aim at substantive policy integration, which can only be achieved by understanding the joint tasks that are hidden within 'organizational silos'. A formal coordinating role can support such an effort of coordination if the SDGs are made a priority matter at the highest level. Only the central government, the President's or the Prime Minister's office for example, could take on the central steering function necessary to achieve effective coordination.

Furthermore, sectorial institutions are often embedded in different policy environments and develop different cultures. Therefore, they may not necessarily be prepared to communicate well in an integrated approach. This fact has to be considered when creating institutional arrangements, as does the education and training of employees. Even highly developed horizontal integration mechanisms at the national level are not be enough to ensure awareness and coherence on their own. Not surprisingly, subnational levels of government that are closer to their citizens often have a better understanding of their needs and particularities. Indeed, to a great extent, public services are delivered, and infrastructure built, at the local level in response to local citizen demands. Local institutions and regional authorities, therefore, tend to be organized in a more holistic, less sectorial manner than government ministries at the national level. This attribute of local and regional authorities suggests that vertical coordination arrangements should be developed to allow for policy integration among national, regional and local governments. Recognizing, however, that when there are a large number of municipalities, coordination with every municipality may not be possible. In such cases, it can be advisable to establish 
one or more coordinating organizations as an intermediary for policy integration between the national and local levels. Such entities can translate and communicate the national SDGs to the local level, thereby allowing local authorities to develop their own sustainability strategies and goals.

This research was conducted with the aim of determining how public organizations, SMEs, citizens and mining companies should effectively cooperate for the sustainable local development partnerships. Within this framework of the article, we have created two research purposes: (1) finding out reasons and interests why the stakeholders shall collaborate through the sustainable development, and (2) determining the factors influencing how the ICDP could effectively foster sustainable local development partnerships.

\section{The Case of Mongolia}

To understand the value of the multiple stakeholder approach in Mongolia, it is important to examine sustainable and integrated local development-partnerships by considering the various significant attributes of Mongolia. These attributes include Mongolia's: history, culture, tradition, state system, legal environment, civil society participation as well as the participant of the private sector. Furthermore, the requirements for sustainable development make it necessary that Mongolia's various regions address environmental protection, the efficient and effective use of resources, income equality, a fair return from natural resource development and the enhancement of the quality of life of each region's citizens. A brief description of how Mongolia's governmental history and governmental structure will provide a fuller understanding of both the challenges and benefits of the multi-stakeholder approach in Mongolia.

After the democratic revolution of 1990, Mongolia shifted from an authoritarian communist regime with a centrally-planned economy towards a democracy with an open market economy. According to the new constitutional law, which was passed in 1992, a semi-parliamentary system which consists of a unicameral parliament and a prime minister-led cabinet, government. The President and Deputies in the National Assembly, the State Great Khural, are directly elected by the citizens. The Deputies in the National Assembly choose the Prime Minister, who leads the cabinet. At state level, the State Great Khural passes laws and the government is responsible for the implementation of these legal acts.

The territorial administrative units of Mongolia are divided into two main groups, which include the capital city and all provinces. The classification of the territorial administrative unit is illustrated in Table 1. The capital city Ulaanbaatar consists of nine districts and one district consists of several Khoroos. On the next lower level, the provinces consist of soums which again consists of several bags. This is how the Mongolian administrative system is classified. 
Table 1. The Number of Territorial Administrative Units

\begin{tabular}{|l|c|c|c||}
\hline \multicolumn{1}{|c|}{ Level } & \multicolumn{2}{c|}{ Number } & Sum \\
\hline \hline First level & Province - Aimag -21 & Capital city -1 & 22 \\
\hline Second level & Soum -330 & District -9 & 339 \\
\hline Third level & Bag -1613 & Khoroo -152 & 1765 \\
\hline Total & \multicolumn{2}{|c||}{ Different territorial administrative units in those three levels } \\
\hline
\end{tabular}

Source: National Statistics Office of Mongolia, https://www.1212.mn (last accessed in February 2020)

At the local level, the Citizens' Representative Assembly of provinces/soums and the capital city/districts have a right to pass an enactment and the governor of the municipal units is responsible for the implementation.

Twenty-four political parties were registered on the Supreme Court registration list by 2016 (Supreme Court of Mongolia) [4] but the power imbalance of the parties is quite large. The two biggest parties, namely the Mongolian People's Party and the Democratic Party, have held the vast majority of elected positions and thus have ruled Mongolia for many years. Since 2012, there has been a trend towards the consolidation of the various parties into these two parties.

The Mongolian economy is mainly based on the agricultural and mining sectors. The Mongolian economy has grown resulting from the positive mining industry development; reaching a recent peak in 2011 with a growth of $17.5 \%$ due to the mining industry boom [5]. Even though Mongolian economists predicted a rather low one-digit increase rate, economic performances have dramatically improved, especially in 2017 and at the beginning of 2018 [6]. However, the rapid growth has been declining due to political instability, constant change in the related legal framework, and low trust of both domestic and foreign investors. Today, Mongolia has a budget deficit and a need to find new financial sources.

To address the economic downturn, several development policy documents have been created and ratified in Mongolia since 1990 [7, 8]. These are the followings:

- National Development Framework of Mongolia, 1996-2015,

- Sustainable Development Strategy of Mongolia in XXI century, 1998-2021,

- Millennium Development Goals of Mongolia, 2005-2015,

- Comprehensive National Development Policy based on Millennium Development Goals of Mongolia, 2008-2021, which is invalid now,

- Green Development Policy, 2014-2030,

- The Agenda 2030 for Sustainable Development of Mongolia (SDG), 2016-2030.

These development documents are future-oriented plans and describe actions for Mongolia to consider based upon its economic, social and environmental situation. For instance, the mission of Agenda 2030 for Sustainable Development 
of Mongolia, 2016-2030 is to reach a local middle-income level in its per capita income by 2030. Furthermore, to become a country with diversified economic sectors, a rich middle class dominating the society, to ensure ecological equilibrium and stable democratic governance [9]. In order to achieve the mission, several development goals are planned within an economic, social, environmental and governance framework. Many actions have to be taken to achieve these development goals, especially in the agricultural, mining, infrastructure sectors of Mongolia [10]. For instance, SDG goals focus on a higher demand for energy (SDG 7) and water (SDG 6), to decline negative impacts on climate (SDG 13), and to encourage the sustainable use of biodiversity and ecosystem services (SDG 14 and 15).

Development issues have been under the structure of nine public authorities since 1990, and now the national development division and public private partnerships/concession division are both integrated in the National Development Agency [10]. The goal of the National Development Agency is to establish a policy which correlates all sector development goals, to create regional development policies, and to take a comprehensive action for attracting national investment for development goals among others.

The effective interoperability of local administration systems can be considered a driving force of development. The local governance system in Mongolia is a combination of local self-governance and state administration. Within the framework of a decentralization policy, local governments have been empowered to receive and spend a certain portion on mineral resource royalties and royalties for use of forest reserves within their local budgets. At the local level, proper management of budget expenditures and the creation of favorable conditions for business activities are very important. At the local level, there is an urgent need for the capacity development of public institutions, harmonization of state and local administration systems, cooperation and involvement of citizens in activities and decision-making processes of state organizations. In regard to decentralization and the delegation of power to local governments, it is very important whether the elected delegates have an open ear for citizens and how they represent the interests of the citizens. Surely, the size of the region and of the population, as well factors such as the state structure and organization, institutional capacity and peculiarities of governance activities have tremendous influence on it.

The process of the implemention of state policies and decisions consists of the determination of possible options to resolve the issues, provision of stakeholder involvement, reflection of their proposals and selection and implementation of the most effective and feasible options. The most important thing for public administrations in regard to proper decision-making concerns regional development that is based on the involvement of citizens, of non-governmental organizations and of entrepreneurs. The issue of sustainable and quality growth in regard to local socio-economic development is crucial. Surely, an integrated policy, cooperation, partnership, mutual understanding and trust are the key influencing factors. 
The establishment of a sustainable integrated partnership beween local administrations, citizens, civil society organizations and companies which conduct acitivities within a given region will create a value for the future. Ensuring equal participation and opportunities for sustainable development of the regions will facilitate the establishment of effective mutual control mechanisms and effective co-operation. For aimags that are rich in natural resources, issues including governance, quality and inclusive socioeconomic growth effective and responsibile state and local administration as well as cooperation beween state administrations, mining companies and private enterprises, non-governmental organizations and citizens, are essential.

\section{Research Methodology and Results}

A partnership in a realistic sense of the meaning is a collaboration between two or more public, private and non-governmental organizations based on equality and equal participation and includes a contract to implement a common objective for the realization of their joint interests. In regard to the different background situation of the stakeholders, they have different roles and interests [11]. The mutual understanding and cooperation of citizens, civil society representatives, mining companies, private entreprises as well public administration organizations will contribute significantly to integrated local development through the provision of the participation of all stakeholders by the bundling of collective efforts into common goals.

The research was conducted in two steps. The main idea and concept of the first step is based on the project which implemented by the Institute for Communal Sustainability and Development between 2015 and 2020 in Selenge, Uvs, Bayankhongor, Uvurkhangai provinces in Mongolia. The aim of the project is finding a way of collaborating Public servants, citizens, civil society representatives, mining companies, small and medium entreprises in four provinces. The project was implemented by the public administration department's professors of the National University of Mongolia.

Within the framework of this Integrated Community Development Partnership (ICDP) project, around 100 civil servants, 60 participants from SMEs, more than 100 citizens and circa 40 mining companies participated in the interviews and questionnaires between 2015 and 2020. Overall, circa 300 representatives participated in the interviews and questionnaires. The number of the interview candidates were almost equal in the four provinces, in Selenge, Uvs, Bayankhongor, Uvurkhangai provinces of Mongolia.

The interview questions focused on the reason why stakeholders should collaborate through the sustainable development process. Ultimately, the main factors of the public organizations, SMEs, citizens and mining companies based on their interview results were revealed. Establishing a "Council for Sustainable Development" 
at the province level which includes representatives of all four of the above mentioned groups was the main achievement of the ICDP project.

Second, we conducted follow-up interviews during the last 18 months. A total of twenty interviewed were completed from individuals in public, private sectors and small and medium enterprises and civil societies in each four provinces. Also, fifty questionnaires were completed from the same groups also within the four provinces. The second follow-up interview focused on the influencing factors how the ICDP could be effectively function.

All participants of the step 2 interviews and questionnaire expressed that the stakeholders shall have mutual trust and suitable capacity. Especially the SMEs and mining companies' representatives emphasized that public organizations shall improve its human resource capacity. More specifically, SMEs and mining companies revealed that civil servants improve their knowledge and skills in regard to collaboration procedure.

If the stakeholders can achieve a consensus and cooperate within the framework of an integrated partnership, they could substantially contribute to the local development. It is because mutual understanding and effective cooperation between the stakeholders can only be established on the basis of a mutual discussion of the issues concerning each of the stakeholders and of possible solutions for those issues for development. The involvement of stakeholders mean a stable, long-term and ongoing process [12] of the participation of stakeholders on issues concerning the use of natural resources and reaching a consensus in regard to how effective this will be. A policy of promoting inclusive, sustainable and quality growth can be achieved through the approval and inclusion of the main key issues indispensable for regional development. These are result of discussions within the integrated local development partnership, in long term regional development strategy and plan of the given region. The the most important goal of the partnership consists in finding the intersection of common interests of the stakeholders whereas each of the stakeholders in the partnership shall represent their own interests, but prioritize the interests of all stakeholders within the framework of partnership activities in order to fulfill their own social obligations and responsibilities.

Local administration: Good institutional capacity is important since it is the key coordinator and decision-maker within the integrated local development partnership, so that the knowledge-level, qualification and productivity of civil servants in those organizations are essential. It is important to focus on interactions between government institutions and the internal affairs of departments of a given organization. It is also important that projects and decisions be discussed openly and transparently by state administrations and local representatives, giving the possibility for public inquiries. The local Citizens' Representative Khural consists on the one hand of the elected representatives of the citizens. It is necessary to form a structure that combines the self-governance of local public administrations and of governing bodies with financial independence, as well equitably allocate the power 
and competence as well the interconnections of local public administrations and of governing bodies. Studies have proven the risk that the collaboration can not be effective if local governments do not have proper governance management [13]. Especially in poor countries, where the development of civil society is not progressive, a situation may arise that the voice of the most vulnerable social groups has not been heard and imbalances have occured during the enforcement of the self-governance principle. International comparative studies show that Mongolia is trying to replicate the experience of countries with strong national and weak local administrations, and this often leads to the observation that Mongolia is ignoring the peculiarities of its own country. While replicating the experiences of other countries seems to be an easy task, it is clear that political decision-makers make decisions without due consideration of national characteristics. With an integrated policy and the research findings of scientists, cannot solve the comprehensive issue of local development, suggesting the need for an elaboration of an integrated strategy.

The key components of a proposed integrated strategy are as follows:

The local administration conducts multiple-faced activities, such as:

- ensuring sustainable local development,

- approving and implement local development policies and guidelines,

- monitoring and ensure compliance with laws and regulations at local level,

- creating a healthy and safe living environment for citizens,

- conducting community support,

- ensuring citizens' confidence,

- monitoring environmental protection and rehabilitation,

- reducing poverty,

- increasing employment and citizens' income,

- creating a favorable business environment,

- effective and efficient utilization of local budget revenues,

but the ultimate goal of the organization consists in creation of favorable conditions and real opportunities for a happy and comfortable living environment for citizens.

The participation of mining companies with a profit-seeking goal in an integrated local development partnership creates the basic conditions for establishment of socially responsible and citizens' friendly development of socially and environmentally friendly mining in line with local development goals. Besides that, it creates the opportunity to jointly develop citizens, non-governmental organizations, government agencies and small and medium enterprises, to support them, to create mutual understanding and resolve issues jointly with them.

Mining companies have the following interests:

- use of mineral resources in the region, to be profitable,

- reach an agreement with other stakeholders and to cooperate with them,

- get support from local administration and from other partnerships, 
- be competitive,

- increase their reputation,

- provide employment to local people,

- prevent misunderstandings,

- prevent protests from citizens and NGOs,

- be socially responsibility.

The participants of the partnership assess the responsibility of mining companies by two key factors: "being responsible to the environment" and "being responsible to the society" [12]. It is important for the mining companies to carry out the process of resource use transparently and within the legal framework. Even though mining companies make a big contribution in regard to creation of employment opportunities for local citizens, conduct of vocational education for citizens, involvement in youth development, concetration of direct and indirect revenue in local budgets and to the local strategic development, the need for the joint implementation of the policy on development of responsible mining in cooperation with local government agencies, citizens and representative of small businesses, reflects the current situation in Mongolia.

Private sector enterprises, and more specifically small and medium entrepreneurs, are based on regional specificities and resources, as well as being sensitive in regard to the daily needs and demand of the local people. Ultimately, they are flexible, liquid and vulnerable to fluctuations in the market. Since they play a vital role in the provision of a range of occupations, some of which require specific qualifications while some do not, in protection of their interests and collection of revenues to local budgets, they are the main component of the regional development. The cooperation between a local administration and the private sector is one part of the public-private partnership.

Small and medium enterprises can:

- implement a short or long term business plan,

- maintain business stability,

- maintain competition,

- maintain income,

- provide quality,

- provide products and services,

- create a new type of business based on mining companies' demand, expand and name work clothes' production, canteens, small-sized trade or production.

Each stakeholder should represent their own interests whereas the requisite conditions to ensure the effectiveness of the partnership are important. Citizen involvement is of key importance within the integrated community development partnership and the main conditions for the realization of poverty reduction of local people, for responsible, high operational effectiveness, for an understanding 
of citizens' desires and the realization of obligations in reality have to be created. On the other hand, it is possible to use the knowledge and education of local citizens with the highest knowledge of local specifics and of educated citizens for local development and development policies. Furthermore, the involvement of citizens in public decision-making processes and activities is important for the strengthening of public confidence in the state. Confidence is a factor which expresses participation. For that, it is a process of the active learning of citizens about the democracy, furthermore, it is a process to make citizens understand the interconnections between social institutions of democracy and to participate on local representations or to enable citizens to control citizens' representatives. Public institutions have the obligation to hear the voice of citizens openly in the public in case if it has been assumed that the activities of a given local administration inadequately express the interests of the citizens. By being close to citizens' interests and wishes, public organizations are specialized in what challenges are faced by citizens and in methods how to solve them. As a result of collaboration between public and local authorities, stakeholders' participation on an understanding of the issues faced by society should be improved. It is now open in the regions that some functions of administrative organizations can be fulfilled by non- governmental organization. Through collaboration with public organizations, the potential to hear the voices of the poorest and most vulnerable groups of the society opens up. In doing so, the strategy of public involvement in governance and integrated local development is achieved.

The interests of citizens and non-governmental organizations are:

- working in a safe and healthy environment,

- access to quality services,

- maintainence of traditional heritage and culture, as well of the original appearance of nature

- safe and sustainable working places,

- increased household income and improved livelihoods,

- getting regularly information in regard to state activities, and

- expressing their viewpoints and including them in partnership policies and decisions.

Local partnerships are directly linked to sustainable development. The UN Declaration on Development states: „It is an integrated political, economic, and socio-cultural process that aims among others to ensure the wellfare of all citizens and the equitable distribution of benefits created in the society based on active and free participation of all citizens and individuals" [12]. Mongolia is among those countries which have a mining dependent economy. Mineral resources cannot be recovered or they can be recovered over a very long period of time, meaning that the efficient allocation of resources and the effective utilization of revenues can prevent negative consequences in the future. Generally, it is the case that environmental 
and social problems affect mining industry stakeholders and their responses [14]. While meeting current needs and demands with revenues from natural resources, efforts and the engagement of citizens in participating in government activities and ensuring the conditions for sustainable and professional public officials, who are fair and respect human rights as well provide for equal participation, are essential in order to make strategic decisions on future-oriented and efficient resources and resource exploitation management.

\section{Discussion}

Cooperation and the achievement of a consensus on the part of local administrations with citizens, non-governmental organizations, mining companies and small and medium sized entreprises within the framework of integrated partnership will substantially contribute to local development. This is because it provides a great opportunity for joint discussion and dealing with issues and problems for each of the stakeholder groups and the most important thing is the mutual understanding and effective collaboration towards development. A policy of promoting inclusive, sustainable and quality growth can be achieved through approval and inclusion of main key issues indespensable for the regional development which are result of discussions within the integrated local development partnership, in long term regional development strategy and plan of the given region. Citizens' involvement is of crucial importance within the integrated community development partnership and is the main condition for the realization of poverty reduction, responsible, high operational effectiveness, understanding citizens' desires and the realization of obligations in reality. Furthermore, the involvement of citizens in public decision-making processes and activities is important for strengthening public confidence in the state and confidence is a factor which expresses participation. Therefore, it may be concluded that stakeholder orientation is an essential factor for performance improvement [15]. For that, it is a process of active learning of citizens about democracy that results in understanding of the interactions between institutions in a democratic society on the part of citizens, getting them interested in being a representative of local bodies themselves or giving them the skills to control and oversee citizen representatives.

The unification of stakeholders: local governments, communities, public organizations and of the private sector - through a joint understanding of the goals and specifics of each stakeholder group - is essential for the elaboration of a strategy on an integrated local development partnership. Even if the local governments develop a comprehensive management framework for all stakeholders, it is evident from experience that success cannot be achieved if the standpoints of participants about their goals and efficiency have not been considered. Even stakeholders are usually concerned about past experiences if they have different perspective [16]. 
The instruments of collaboration used in the regions with respect to aimags are dependent on the initial position of the parties. It is worth mentioning that that positive steps have been achieved in the praxis, suggesting the possibility of successful implementation of these multi-stakeholder partnerships through the sustainable provision of equitable stakeholder engagement in the long run in the four selected provinces of Mongolia.

Nonetheless, the current political and socioeconomic situation in Mongolia proves the importance of the issue of the consistent implementation of an approved long term strategic plan in the form of a decision on the involvement of all local stakeholders. This is for the purpose of the prevention of it being used only as instrument for the fulfillment of election policies and commitments given during elections, which represent a "new" not far-sighted governance form that is being to become a tradition as a result of political elections in Mongolia.

Since the above explained interconnections between representatives of stakeholder groups, both among each other and with regional public administrations, are important for any increase in citizen participation and for the improvement of their living conditions, the issue of how to bring all the contributions of representatives of various social groups to a joint effort is essential. We may not forget that the existence of one or more independent public and private service providers is more likely to neutralize and even bring negative results rather than lead to positive consequences.

Linkages and interconnections between local government agencies have the most importance. The right of local administrations to determine important political goals directed towards wellbeing of local citizens, as well to bundle the interests of representative stakeholder groups of the community and to use them to achieve the above goals, is given within the framework of a democratic law. For local citizens it is clear that it has to be thouroughly reflected and elaborated upon, since only local administrations of the given region bear the responsibility. In addition, a challenge faced by local authorities consists of the limited resources available to meet their goals.

Another stakeholder group in the ILDP are small and medium sized enterprises (SMEs) which have a real impact on local socio-economic development and employment situation, especially in regard to women's employment and income levels. "They are getting help and support in regard to capacity strengthening in order to become a reliable supplier of mining companies. Capacity development activities in regard to SMEs are directed to increase of production, meeting of quality standards, as well as improvement of management and contract management". Since the values, roles and responsibilities in the community as well as management methods of stakeholder groups [17] within integrated community development partnership are different, effective and creative forces shall be created through the process of partnering itself. 
What will be important in strengthening the sustainable partnership for the future is illustrated in Figure 1:

- collaboration within independent systems,

- mutual activities and trust,

- focus on the performance and capability of partners,

- to pay attention on human resources and capacity,

- to be based on business cases,

- to implement a joint control system,

- to establish internal criteria for collaboration,

- to implement a set of teamwork activities,

- challenge, compilation and coordination of different ways of dealing with interactions between political and business activities,

- to create and integrated system for cooperation management.

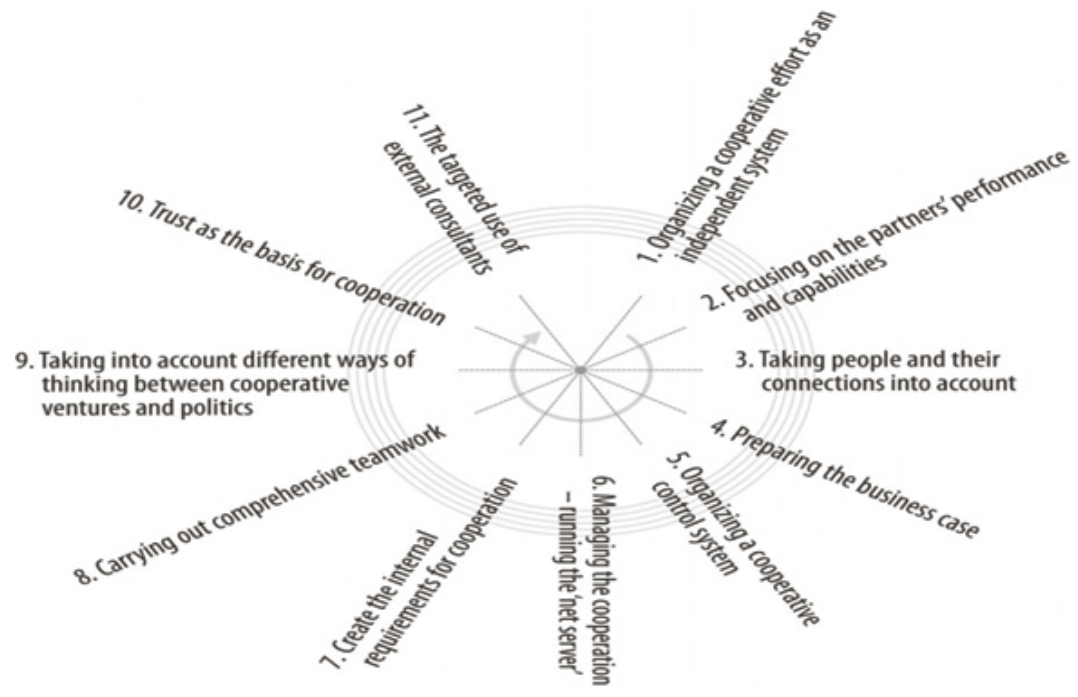

Fig. 1. Strengthening the sustainable partnership for the future Source: [17]

International experience in partnerships show the need to focus on the governance of cooperation and the future. Cooperation or partnership is an optimal model which is effective and combines the results and achievements of multiple stakeholders. From the research over the past few years we conclude that beginnings have been set by the following activities:

- mutual activities and trust,

- focusing on the performance and capability of partners,

- to pay attention to human resources and capacity,

- to implement a set of teamwork activities. 
Certainly, there is a need to verify and improve factors and activities directly or indirectly related with the above factors on the basis of detailed analysis of given factors and activities and there are many challenges in regard to the improvement of other influencing factors in a systematic way. Optimal organization and coordination among partner organizations is clearly essential. Cooperation with research, training and advisory institutions within the framework of the partnership would lead to even more effectiveness. Even though the interests of the parties are important, it is critical to keep in mind that social responsibility and public interest are the first priority so that the activities shall be based on fundamental pillars such as transparency, efficiency and accountability. It is also important to provide an opportunity for equal participation to all stakeholders. Directly granting preferred rights to one group of stakeholders would cause risks in regard to the viability of a true partnership. Since the partnership is an independent social system, we are confident that it will contribute to sustainable local development which is based on rational structures, necessary resources and trust.

\section{Conclusion}

This exploratory study sought to examine the theoretical understanding of how institutional arrangements for sustainable local development partnerships in mineral resource-rich countries are created. A mixed-methods approach was used, consisting of both quantitative and qualitative methods including experts' interviews, reports and documents analysis, and a questionnaire issued to officials and citizens from selected resource-rich provinces of Mongolia.

The key findings of the study are as follows:

- there is a weak understanding of partnership-related local community development among stakeholders,

- there is weak collaboration between state and local administrations,

- there is a low capacity of public sector human resources at the local administrative level.

Also, the Council for Sustainable Development at the province level helps to enhance the collaboration between the partnerships. The main success results of the council are revealed that among others these provinces have passed the Total Quality Management criteria, the capacity of civil servants has been improved. Also, it has been considered as a model case for the sustainable local development partnerships to the remaining provinces of Mongolia.

Future studies are needed to determine the best ways of establishing multi-stakeholder engagement, including public organizations at both national and local level, citizens, mining companies, small and medium entreprises. Moreover, the efforts of multi-stakeholder engagement in the four provinces of Mongolia should be 
investigated in more depth. For instance, the coherence of the Council for Sustainable Development of the provinces could be investigated as well.

To conclude, a long term strategic planning and management which involves all stakeholders' interest in decision making procedures should be created. In addition, building both horizontal and vertical institutional arrangements based on the proper participation of related stakeholders is the most essential element of a successful sustainable local development partnership.

\section{Disclosure Statements}

The authors declare that they have no relevant or material financial interests or conflicts of interest relating to the research described in this paper.

\section{References}

[1] Dodds F.: Multi-stakeholder partnerships: Making them work for the Post-2015 Development Agenda. Global Research Institute, University of North Carolina, 2015.

[2] Nel D.: Multi stakeholder partnerships as a mechanism for creating public value. Department of Public Management and Governance, University of Johannesburg, 2014.

[3] Vermus M., Kubina M., Koman G., Ferenc P.: Ensuring the Long-Term Sustainability Cooperation with Stakeholders of Sport Organizations in SLOVAKIA. Sustaibility, vol. 10, no. 6, 2018, pp. 1-19.

[4] Supreme Court of Mongolia: The List of the Political Parties in Mongolia. http://www.supremecourt.mn/nam [access: 28.08.2020].

[5] Altantsetseg Sh., Khandtsooj G., Gregory S.: Mongolia Economic Update. The World Bank Group in Mongolia, 2013.

[6] Nganou J.-P., Batsuuri D., Nyanzi S., Shiilegmaa A.: Mongolia Economic Update: Fiscal Space for Growth, Role of Public Investment Spending Efficiency. The World Bank, 2018.

[7] Doljinsuren J.: National Development Policy of Mongolia. The Development Policy and Planning Division, National Investment Agency of Mongolia, 2017.

[8] State Great Khural: Mongolian Law on the Development Policy and Planning. 2015.

[9] The Agenda 2030 for Sustainable Development of Mongolia, The Parliament Resolution No 19, from 2016.

[10] Munkhbold A.: National Development Policy of Mongolia. Research and Analysis Department of National Investment Agency of Mongolia, 2017.

[11] Lam J.S.L., Yap Y.: A Stakeholder Perspective of Port City Sustainable Development. Sustainability, vol. 11, no. 2, 2019, pp. 1-15. 
[12] Enhancing stakeholder engagement in environmental protection-II project: Sustainable development-responsible use of natural resources. Ulaanbaatar 2015.

[13] Rhodes R.A.W: Understanding Governance: Policy Network, Governance, Reflexivity and Accountability. Open University Press, 1997.

[14] Que S., Wang L., Awuah-Offei K., Chen Y., Yang W.: The Status of the Local Community in Mining Sustainable Development beyond the Triple Bottom Line. Sustainability, vol. 10, no. 6, 2018, pp. 1-11.

[15] Ferro-Soto C., Macías-Quintana L.A., Vázquez-Rodríguez P.: Effect of Stakeholders-Oriented Behavior on the Performance of Sustainable Business. Sustainability, vol. 10, no. 12, 2018, pp. 1-19.

[16] Smulders-Dane S., Smits T., Fielding G., Chang Y., Kuipers K.: Learning from Regional Sustainable Development in the Netherlands: Explorations from a Learning History. Sustainability, vol. 8, no. 6, 2016, pp. 1-17.

[17] Grossman R.: Politics and Civil Society. [in:] "Democracy, challenges and potentials" international conference, Ulaanbaatar 2011 [conference paper]. 